archives-ouvertes

\title{
Two scenarios for carbon capture and storage in Vietnam
}

\author{
Minh Ha-Duong, Hoang Anh Nguyen Trinh
}

\section{To cite this version:}

Minh Ha-Duong, Hoang Anh Nguyen Trinh. Two scenarios for carbon capture and storage in Vietnam. Energy Policy, Elsevier, 2017, 110, pp.559-569. <https://doi.org/10.1016/j.enpol.2017.08.040>. <hal01550029>

\section{HAL Id: hal-01550029 \\ https://hal-enpc.archives-ouvertes.fr/hal-01550029}

Submitted on 29 Jun 2017

HAL is a multi-disciplinary open access archive for the deposit and dissemination of scientific research documents, whether they are published or not. The documents may come from teaching and research institutions in France or abroad, or from public or private research centers.
L'archive ouverte pluridisciplinaire HAL, est destinée au dépôt et à la diffusion de documents scientifiques de niveau recherche, publiés ou non, émanant des établissements d'enseignement et de recherche français ou étrangers, des laboratoires publics ou privés. 


\title{
Two scenarios for carbon capture and storage in Vietnam
}

\author{
Minh Ha-Duong $\quad$ Hoang Anh Trinh Nguyen²
}

2017-05-24

\begin{abstract}
Vietnam plans to develop dozens of new coal-fired power generation units over the next 20 years. In order to reduce emissions, it may appear necessary to dispose of these plants' $\mathrm{CO} 2$ by burying it in deep underground geological formations instead of releasing it into the atmosphere, using Carbon Capture and Storage (CCS) technology. We show that CCS has a technical potential in Vietnam. To discuss under which economics conditions this potential could actualize, we examine two scenarios for 2050. In the first scenario, CO2 is used in Enhanced Oil Recovery (EOR) only. The second scenario considers CCS deployment in coalbased power plants, on top of using it for EOR. In both scenarios, a few gas-fired CCS power plants are build, reaching $1 \mathrm{GW}$ in 2030, supported by Enhanced Oil Recovery and international carbon finance. The decision point where the two scenarios diverge is in 2030. A scenario to switch all currently existing or planned power plants to low-carbon by 2050 is to retrofit 3.2 GW of coal-fired capacity and install 1.2 GW of gas-fired capacity with CCS every year, starting in 2035 for 15 years. Capture readiness would lower the costs of using CCS in Vietnam, but is not mandatory today.
\end{abstract}

\section{Highlights}

- CCS is relevant for Vietnam: power capacity from coal and gas is expanding faster than $+1 G W$ per year

- Lack of policy interest and the CCS costs are the biggest barriers for CCS development in Vietnam

- In 2 scenarios, gas-fired CCS plants reach 1GW in 2030, supported by EOR and carbon finance.

- Low carbon scenario: retrofit 3.2 GW (coal), install 1.2 GW (gas) with CCS/year 2035-2050.

- Capture readiness would lower the costs of using CCS in Vietnam, but is not mandatory today.

1 CIRED/CNRS, minh.haduong@gmail.com

2 CleanED/USTH, hoanganhelec@gmail.com 


\section{Introduction}

Boden, Marland, and Andres (2013) measured that fossil fuel CO2 emissions to the atmosphere in 2014 were $9.8 \mathrm{GtC}$, and coal burning was responsible for $42 \%$ of those. This is not sustainable, and all the more worrying that countries like China, Vietnam, Indonesia, and India are adding coal-based power generation units faster than countries like Germany or USA are retiring them. To make coal-power generation compatible with a low-carbon economy, the industry has been demonstrating the technology of $\mathrm{CO} 2$ capture and storage (CCS), to dispose of the CO2 underground instead of releasing it in the atmosphere (Metz et al. 2005).

CCS technology seems a priori relevant for Vietnam, a lower middle income country with billion tons of coal reserves, who as of 2016 officially plans to open one new $500 \mathrm{MW}$ goalfired electricity generation unit every three months in the years to come (The Government of Vietnam 2016). Yet CCS is not in the energy policy agenda in the country, according to our survey of local stakeholders (H.A. Nguyen-Trinh and Ha-Duong 2015) who furthermore anticipated that CCS would remain a low priority question in Vietnam for the next twenty years.

We argue that the prospective availability of CCS at some point in the future do raise questions about the power plants being built today, in 2016. These plants will probably still be operating in 2050, should they be built with a CCS retrofit in mind? This is of course only interesting to do if there is a plausible perspective that the plant will have to be retrofit with CCS in the future. In order to help the reader assess the plausibility of such perspective, this manuscript exposes two long-term narrative scenarios about the prospect of CCS in Vietnam.

This manuscript is organized as follows. Section 2 describes what CCS is and what is captureready, focusing on the relevance of these technologies for Asian countries. Section 3 reviews the literature on CCS in Vietnam. We show that the industrial and geological conditions are favourable for carbon dioxide storage, even if neither capture readiness nor CCS RD\&D is on the political agenda. Section 4 exposes two visions of CCS technology penetration in Vietnam up to 2050. The first scenario limits it to Enhanced Oil Recovery (EOR) - a technology which could help the country extract more oil from existing fields and defray the cost of CCS. The second scenario describes a future where, in addition to EOR, CCS comes to be used at coalbased power plants, justifying capture readiness. In Section 5, we compare quantitatively the High CCS scenario to a baseline without CCS based on a national energy mix simulation model with twelve technologies: three fossil fuels, big hydro, four renewable energy technologies, coal CCS, gas CCS, bio CCS, and imports. This model computes the system Levelized Cost of Electricity Generation (LCOE) and the system greenhouse gases emissions. Section 6 discusses policy implications and concludes. 


\section{Literature review}

\subsection{Carbon capture and storage exists at the industrial scale}

This section illustrates how it is technologically feasible to capture CO2 emitted from burning fossil fuels, compress it and then bury it underground in geologic formations for a very long time (Metz et al. 2005).

According to (GCCSI 2016), fifteen large scale CCS demonstrations projects were operating in 2015. The majority was deployed in the United States and Canada, with 2 in the EU and 3 in the rest of the world. None was in Asia. But when it comes to development, the focus of moves from projects in North America (three in advanced planning) will be towards projects in Europe and China (a combined eight in advanced planning). These examples show that CCS can be used to reduce emissions from fossil fuel burning installations and from fuel processing facilities. They substantiate the claim that CCS has the potential to allow deep cuts in greenhouse gases emissions. Although CCS is expensive compared to the value of avoided $\mathrm{CO} 2$ in most carbon finance markets today, some affluent countries like Norway have at times imposed CO2 taxes higher than the cost of CCS. There are not many alternatives to control emissions for large industrial installations, besides shutting them down.

The BLUE Map scenario described in (IEA 2008) quantified the role that CCS could have in a portfolio of actions to mitigate $\mathrm{CO} 2$ emissions, particularly those coming from coal power plants. The BLUE road-map proposed an ambitious CCS growth path with 100 projects globally by 2020 and over 3400 projects by 2050. In Asia, China and India are together were to implement 21 CCS projects by 2020 and 1260 CCS projects by 2050, and to account for $37 \%$ of total global CCS projects by the same year.

\subsection{CCS in Southeast Asia and China}

CO2 emission of the East Asia Pacific region have increased more than threefold over the past twenty years. In a report by the Asian Development Bank, (Tharakan 2011) estimated that the primary energy demand in the Southeast Asian countries (ASEAN) will increase by about $76 \%$ during the period 2007-2030. Of all energy sources used in the region, coal would increase the most. As a consequence, energy-related emissions are set to double by 2030 compared to 2007. World Bank (2010) warned in another study that under the continuation of current policy, emissions of CO2 would double from about 7.2 Gt in 2009 to $14.3 \mathrm{Gt}$ by 2030 in China and EAP5 countries.

Based on a regional study of climate change economics including Indonesia, Philippines, Thailand and Vietnam, (Asian Development Bank (ADB) 2009) argued that in Southeast Asia, mitigation through CCS could become feasible as the carbon price rises toward 2050, with reduction potential of up to $22 \%$ of emissions under the BAU scenario in addition to consumption changes and fuel switching.

In spite of these perspectives, CCS is not a technology priority for South East Asian countries. Energy policies are understandably more focused on contributing to sustained economic growth, addressing poverty and security. Even in climate change policies, CCS takes a 
backseat at best. In Vietnam for example, the overall climate policy strategy is to orient the domestic resources towards adaptation, and leave mitigation leadership to international resources.

The regional interest is mostly oriented towards Enhanced Oil Recovery (EOR). For example, Indonesia began examining the EOR potential since 2003 (Indonesia CCS Study Working Group 2009). Overall, the existing CCS action in South East Asia is one-off and project oriented, it has not progressed towards locationally appropriate CCS regulatory frameworks.

China is the major emitter of greenhouse gases in the region, and about $90 \%$ of its emissions come from burning of fossil fuels. (H. Liu 2010) argues that the deployment of the full range of low-carbon technologies, including CCS, is essential for the PRC to decarbonise its power sector and achieve long-term climate change mitigation goals. For many years, approximately $1 \mathrm{GW}$ of new coal-fired power plants began construction in China every week. Using CCS could reduce of CO2 emissions from the Chinese energy sector by 100 and 380 million tons in 2030 and 2050 respectively (CCICED 2009). The government promotes CCS research, development and demonstration since 2005 and continuously increases the program's funding (ADB 2012, 20012). (Zhu and Fan 2013) focused on the investment decision to retrofit an existing supercritical pulverized coal (SCPC) unit with CCS technology and four uncertainty factors: electricity price, carbon price, CCS investment cost and CO2 additional O\&M cost. The study found that the CCS retrofit investment decision is most sensitive to additional O\&M costs for CO2 capture, and the existing level of CCS technology, but the existing policy framework do support the plant owner to retrofit the existing SCPC unit with CCS.

\subsection{Capture-ready concept in plant design and regional planning}

In 2010, the three main organisations working on CCS defined that CCS Ready facility is a large-scale industrial or power source of $\mathrm{CO} 2$ which could and is intended to be retrofitted with CCS technology when the necessary regulatory and economic drivers are in place. The aim of building new facilities or modifying existing facilities to be CCS Ready is to reduce the risk of carbon emission lock-in or of being unable to fully utilize the facilities in the future without CCS (stranded assets). CCS Ready is not a CO2 mitigation option, but a way to facilitate CO2 mitigation in the future" (Christopher Short 2010).

The plant is designed to be technically capable of retrofit and built in an appropriate location where it deals with potential roadblocks such as conflicting land use, environmental and other permits, public awareness, and identification of service providers, see (Bohm, M.C. 2007; IEA 2007) for more details on the engineering requirements.

Building a capture ready plant costs more, because additional constraints bear on the project. For example, it may lead to choose a more sophisticated combustion technology than classical boilers. To examine the political feasibility and techno-economic aspects of capture readiness, (Sekar, R.C. 2007) showed that an Integrated Gasification Combined Cycle (IGCC) plant is more expensive to build and operate than a Pulverize Coal (PC) plant, but less expensive to retrofit for CO2 capture. Bohm M.C. (2007) expanded upon this analysis to include the option 
of building a capture-ready IGCC plant in addition to a baseline plant, pointing out the lower carbon tax level at which a retrofit is economically justified.

Building capture ready is crucial to prevent a 'carbon emission lock in' in countries building up a coal-based power generation capacity. (Li, Liang, and Cockerill 2011) examined 74 coalfired power plant sites in China found that only 19\% of sites appear to have a high retrofitting potential. Paying for the capture-ready real option cost as insurance does not make business sense. The bottom line would only be impacted if there were under credible treats of CO2 emissions mitigation measures.

Regional planification can facilitate the adoption of capture ready in new coal plants. (Zhou et al. 2013) investigated CCS options for Guangdong, the most economically developed province in China. The project “Guangdong, China's First CCS Ready Province” (GDCCSR) provides a comprehensive review to decision makers on the necessity, feasibility, and roadmap for the CCS development in the province. (Li et al. 2011) evaluated the benefits of a 'CCS Ready Hub’ approach and a regional 'CCS Ready' strategy, in the case study of Shenzhen city in southern China. It found that financing 'CCS Ready' at regional planning level can reduce the overall cost of building integrated CCS systems. It recommended that the location of existing large emissions sources should be taken into account when planning new CCS ready plants or a CCS ready hub. 


\section{The conditions for CCS in Vietnam}

This section reviews the drivers influencing CCS in Vietnam at the 2050 time horizon. We look first at the fundamentals of the economy/energy system, then examine the geologic conditions, and finally review other studies on CCS and on the energy system scenarios.

\subsection{Demography, economy, fossil fuel reserves and coal plants under construction}

Vietnam is a densely populated country. During the period 2000-2010, annual growth rate of population density in Vietnam was 1.7\%, reaching 264 persons per km2 by the end of 2010 . The population is concentrated in the Mekong and Red river deltas. It population will reach 101.6 million by 2025, with population growth slowing somewhat over time. In 2012, about 70 percent of the population living in rural areas, however growth in urban population greatly has been outstripping rural population growth, as the rapid urbanization and industrialization processes in Vietnam.

Vietnam's economic growth rates have been at high for the last 25 years, around seven percent annually. In next decades, Vietnam expects to keep relatively high economic growth rate as it catches up with the more affluent countries and has a dynamic demography. The energy demand is increasing faster than the economy by a factor 1.7.

\begin{tabular}{lll}
\hline & Total proved reserve at end of $\mathbf{2 0 1 5}$ & Reserve/Production ratio \\
Oil & 600 million ton & 33.3 years \\
Natural gas & 600 billion cubic meter & 57.9 years \\
Coal & 150 million tonnes & 4 years \\
\hline
\end{tabular}

Table 1: Vietnam fossil fuel reserves. Source: (British Petroleum 2016)

Table 1 displays Vietnam's fossil fuel reserves. At the current production rate Vietnam would exhaust its proved reserves of oil before 2050, and natural gas by 2075. These numbers evolve over time, as exploration finds additional reserves and the production levels change over time. This is particularly true for Coal, where the numbers from BP are very far from those in the master plan on the development of the coal industry (Nguyen Tan Dung 2016). As of December 31, 2015, total coal reserves and resources were estimated at about 48.88 billion tons, including around 2.26 billion tons in reserves and 46.62 billion tons in resources, of which 0.34 billion tons are peat. Coal production of Vietnam increased from 34 million tons in 2005 and seems to have reached a peak at 45 million tons in 2010 then down to 41 million tons by the end 2015 (GSO 2016).

The capacity of coal-fired power plants in Vietnam has increased from $0.5 \mathrm{GW}$ in 1995 to 13 GW by the end 2015 (EVN, 2016), and the future looks as dramatic. The capacity of all the coal-fired plant in Vietnam, operating or at various stages of construction, permitting, planning or announcement adds up to 57 GW. The Power Development Plan VII Adjusted (T. D. Nguyen 2016) targets 55 GW of coal generation capacity in 2030. In other words, Vietnam plans to open build about one $500 \mathrm{MW}$ of new coal-fired power installed capacity unit every 
three months annually during the period $2010-2030$. Coal would provide $56 \%$ of the total power generated in the country by 2030 .

The general objective of the Power Development Plan VII Adjusted (The Government of Vietnam 2016) is to drive the electricity sector of Vietnam towards to a more sustainable future in which low carbon technologies are encouraged and supported for both electricity supply and demand sides. According to this Plan, the investors of power plants have to applied advanced technologies to increase efficiency of the generation process and to reduce $\mathrm{CO} 2$ emissions from burning fossil fuels. Although carbon capture and storage technologies are not specifically mentioned in the Plan, with they are still considered as promising solutions for cutting $\mathrm{CO} 2$ emissions from coal-fired power plants. Given that coal-related $\mathrm{CO} 2$ emissions would account for more than $85 \%$ of the total CO2 emissions from the electricity sector by 2030, applying CCS technologies in the power sector could help Vietnam achieving its emission reduction targets (8-23\% as compared with the baseline by 2030) committed in the COP21 in 2015.

\subsection{A promising geological storage potential}

The French geological survey (BRGM), in collaboration with its Vietnamese counterpart KVN, examined the potential for storing CO2 in Vietnam's underground (BRGM 2009; KVN 2009). The study screened the location and capacity of depleted oil/gas reservoirs; deep saline aquifers; and coal formations which satisfied the constraints: (i) The sediment formations should be deeper than 1000 meters; (ii) they should be 20 kilometers away from major faults or known oil fields; (iii) no more than 100 kilometers away from a CO2 source emitting more than $2.5 \mathrm{MtCO} 2$ /yr. A study, with preliminary assessments of storage sites, emissions sources, transport links and regulatory environment, revealed promising opportunities in Vietnam for storing carbon emissions geologically and for commercial use in EOR and ECBM projects (KVN 2009).

Figure 1 shows that there are promising offshore storage opportunities near most Vietnamese coal power plants. Regarding capacity, the BRGM/TKV study examined the quality of reservoirs identified in the Vietnamese offshore basins and the size of these basins. Results allows to forecast more important storage capacities than in the case of the Utsira reservoir in the North Sea, which is one of the most emblematic reservoir in the world and could enable the storage of CO2 for a great share of the European needs (20 000 to $60000 \mathrm{MtCO} 2$ ).

As first steps in Vietnam, there appear to be specific opportunities to:

- Enhance oil recovery while storing CO2 in the river basin area of Cuu Long.

- Enhance coal bed methane recovery while storing CO2 in Quang Ninh coal basin.

- $\quad$ Store CO2 into depleted oil fields in Cuu Long, Song Hong, and North end.

These opportunities are not being exploited presently. 


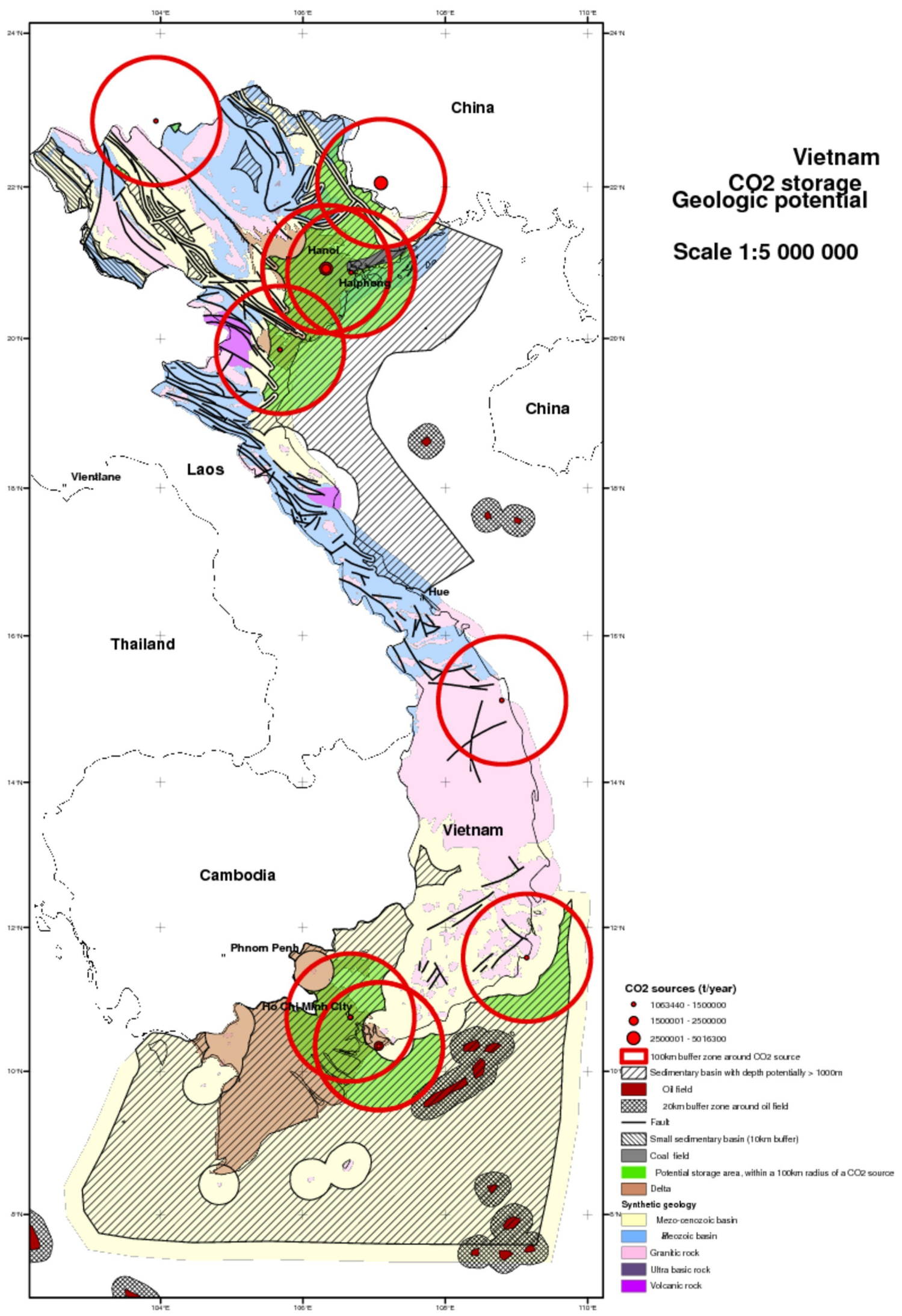

Figure 1: Geological formations potentially favorable for $\mathrm{CO}_{2}$ storage in Vietnam (BRGM/TKV 2009, 34) 


\subsection{Studies on CCS in Vietnam}

Several studies on CCS in Vietnam have been conducted, all sponsored internationally. They demonstrate that there is an international interest within the South-East Asia region about the role of CCS as a mitigation option against climate change in Vietnam. IEA and the Global CCS Institute carried out a series of workshops to introduce CCS to national ministries in Vietnam and Malaysia during early 2010.

The subsequent (ADB 2012) study is perhaps the most complete document available on CCS in Vietnam. The study found that the top 14 oil and gas fields offshore Vietnam offer 900 megatons of CO2 storage capacity. And that CCS increases the levelized cost of electricity from supercritical coal plants by $78 \%$ and from natural gas combined-cycle plants by 55\%. The study proposes a roadmap to reach the first commercial-scale CCS operation in Vietnam in twenty years.

Petro Vietnam (PV) in collaboration with Mitsubishi Heavy Industries conducted two feasibility studies for CO2-EOR in the Rang Dong (Aurora) and Bach Ho (White Tiger) oil field. It proposed further expansion to 7.4 million tons per year, resulting in the recovery of an average of 50 thousand barrels of crude oil per day (DNV 2005; Nubuo Imai and Scott Reeves 2004). Vietnam submitted the White Tiger CCS project to the UNFCCC for funding under the Clean Development Mechanism (CDM). This was the first CCS-based CDM proposal, registered in 2005. It would have had a high demonstration value. The Executive Board of the CDM has not approved any CCS project to date. Doing so would probably have flooded the market and driven down the price of Certified Emission Certificates (CER). It is only at the Cancun conference (COP-16, 2010) that the United Nations decided that CCS could be eligible under Clean Development Mechanism (CDM) in principle. But this is a posthumous victory: the CER price is too low to interest investors, the principle decision leaves a number of practical issues to be resolved, and the whole Kyoto Protocol system has been quietly left to die at the COP 21 in 2015.

\subsection{Environmental impacts and risks of CCS technologies}

Although there is clear evidence of accidents from CCS projects, there are still concerns regarding the technical risks of the construction and operation of these projects in Vietnam (H.A Nguyen-Trinh and M Ha-Duong, 2015). Experts in Vietnam are familiar with technologies to implement CCS projects, but the combination of these technologies is still a new concept to the public. Little experience has been accumulated in Vietnam because only one CCS project has been implemented in the country: the White Tiger Enhanced Oil Recovery CCS project. The main purpose of this project is the recovery of more oil, rather than collecting and injecting CO2 into the oil field. Notably, one expert who works for the Ministry of Industry and Trade (MOIT) said that "The purpose to increasing 8\% of oil production of this CCS project was not achieved during its operation. The oil production has decreased after integrating the CCS facilities". This reduction may be caused by the dissolution of gases and oil during the process of injecting CO2 into the oil field. Then, experts are concerned regarding accidents or unexpected events that could occur in power 
plants or storage sites during the long lifetime of CCS projects. An expert at MOIT emphasized that "Vietnam is highly affected by natural disasters such as hurricanes, floods and earthquakes. This point should be seriously considered when implementing any CCS project in the country and to foresee the technical risks".

Leakage of stored CO2, both onshore and offshore, is a potential environmental risk (Blackford et al. 2013; Pearce et al. 2014; Smith et al. 2013; Steven, Smith, and Colls 2010). Experts in Vietnam suppose that large-scale CO2 storage would negatively affect geological systems, such as underground water or faults in the rock layers, as well as marine ecosystems in the case of offshore storage. In addition, CCS construction from CO2 emitting sources to the storage could damage local environments. However, two experts who participated in studies on CCS's potential in Vietnam and other Southeast Asian countries said that "the risk of CO2 leakage is not very important because both international and national experiences in the natural gas industry have shown that Vietnam can operate and manage technologies to transport and store gases safely"

\subsection{CCS in scenarios of the Vietnam energy system}

Mainly developed countries that are under an obligation to reduce their $\mathrm{CO} 2$ emissions continue CCS projects. In contrast, developing countries such as Vietnam do not give priority to the technology partly because of their difficulty in financing other development projects, such as in the power sector.

\section{Power generation capacity (GW) in Vietnam, 2040 \\ for different $\mathrm{CO} 2$ value target \\ घ Total $\square$ with CCS}

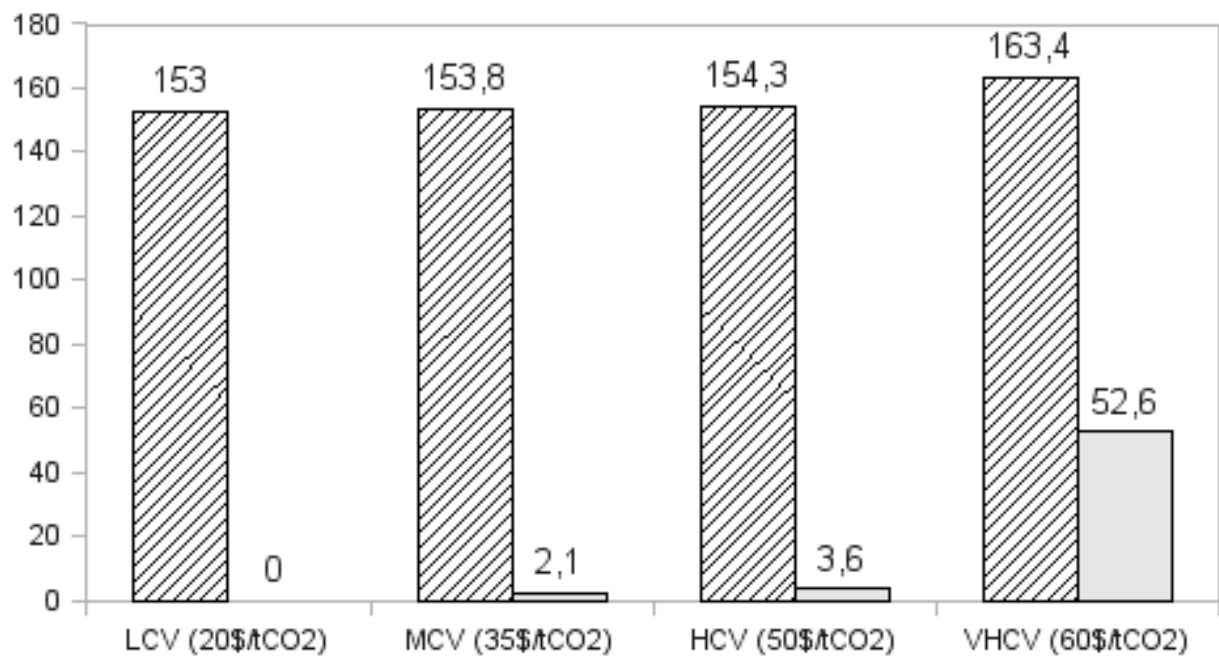

Figure 2. Future Vietnam power generation mix capacity in different studies (Unit: GW). S1: the 7th Power Development Plan, S2: N.T. Nguyen (2011), S3: H.A. Nguyen et al. (2016), S4: Khanh Q.Nguyen (2008)

Figure 2 compares the result of four different studies about scenarios planning for electricity generation capacities of Vietnam up to 2030. In the figure, the S1 scenario corresponds to the 
official PDP7 plan published in 2011, before the 2016 adjustment. CCS technologies unfortunately are not under consideration in this national plan even the government still develops the power sector with the dominance of fossil fuels as coal and gas.

S2 scenario is from (N. T. Nguyen 2011). This is the only study among four to examine the role CCS as climate policy instrument in the Vietnamese power sector. It found that with the carbon price increasing gradually from 5 US\$/t CO2 in 2010 to 60 US\$/t CO2 by 2040, Vietnam would have a generation capacity of $52.6 \mathrm{GW}$ by 2040 using CCS, accounting for $24.4 \%$ of the total capacity in 2040. These outputs result in $1.3 \mathrm{Gt}$ of CO2 abated in the power sector of Vietnam during the period from 2030 to 2040.

S3 refers to (H.A Nguyen-Trinh and Ha-Duong 2016). It proves that Vietnam could purse energy conservation and carbon emission reductions without impeding economic growth. S4 by (K. Q. Nguyen 2008) introduced external costs in the power sector that changes the generation mix: $11 \mathrm{GW}$ less of coal power plants, but $3 \mathrm{GW}$ more of gas turbine and $15 \mathrm{GW}$ of geothermal, wind, and biomass.

These examples show that a majority of studies, to reduce $\mathrm{CO} 2$ emissions from the future electricity generation in Vietnam, focus on renewable energies, energy efficiency, and external costs, and give little specific attention to CCS technologies. This is still true in the most recent reports. Kimura and Phoumin (2016) recognizes the importance of low carbon coal, but offers no specific vision for deployment. The Vietnam energy sector assessment and roadmap by Aruna K. Wanniachchi et al. (2016) from ADB does not mention CCS at all. The World Bank report on Vietnam low-carbon development path by Audinet et al. (2016) mentions once CCS in the list of acronyms and once in the bibliography, but it is not mentioned in the text or used in the scenarios.

This conclusion goes well with an argument that Vietnam could take advantage of its various renewable energy sources to meet its power demand as well as reduce $\mathrm{CO} 2$ emissions rather than burn coal then apply expensive technology such as CCS. Many experts agree that CCS technology should reinforce renewable energy rather than replace it (H.A Nguyen-Trinh and M Ha-Duong, 2015). 


\section{Two scenarios narratives for CCS in Vietnam}

During the COP21 in December 2015, Vietnam, in its Intended Nationally Determined Contributions (INDCs) to UNFCCC, has committed its CO2 emission reductions with ambitious targets by 2030. According to the INDCs, with domestic resources of the country, Viet Nam will reduce GHG emissions by $8 \%$ compared to BAU by 2030 . The target could be increased to $23 \%$ if the country could receive international supports through bilateral and multilateral co-operations, as well as through the implementation of new mechanisms under the Global Climate Agreement, in which emission intensity per unit of GDP will be reduced by 30\% compared to 2010 levels. This commitment has increased pressure for Vietnam to reduce their $\mathrm{CO} 2$ emissions in next decades. In the context, the country may seek all low carbon options to drive the economy as well as the energy sector. CCS technologies therefore may have greater opportunities in power generation sector, given that this sector would contribute up to $80-90 \%$ of the total CO2 emission. In this current section, the authors sketch two scenarios for CCS development in Vietnam with consideration of factors/conditions that the two scenarios are based on.

\subsection{The social conditions}

Table 2 presents influences and interests of different stakeholder groups in CCS deployment in Vietnam. Most groups have a low interest in the technology, since there is no actual project on the ground in Vietnam. Domestic Environmental NGOs lobby for the nation to stop building new coal power plants as soon as possible, we have not heard them take a position on CCS. Neither did we hear about CCS from the national power generation company Electricity of Vietnam or the national coal mining company.

\begin{tabular}{lll}
\hline High stakeholder influence & Low stakeholder interest & High stakeholder interest \\
& Policy makers & CCS industry and researchers \\
& Local community/government & International carbon finance \\
& Electricité du Vietnam & Fossil-fuel power industries \\
& VinaCoMin & PetroVina \\
& Local and international media & \\
& Investors \\
\hline Low stakeholder influence & Renewable energy industries & \\
& Domestic environmental NGOs & \\
& Education and training institutes & \\
\hline
\end{tabular}

Table 2: Influences / interest matrix of different stakeholder groups in Vietnam

From their perspectives, stakeholders have different interests and influences on the CCS activities, either at local level or global level. The concerns of local level are associated with delivery of local benefits, socio-environmental aspects and heath/safety impacts. Local communities/governments, industries and investors often deal with issues in this level. At the global level, policy makers or research institutes give discussions on climate change and development of the economy as a whole. 


\begin{tabular}{ll}
\hline Strengths & Weaknesses \\
-The ability to issue policies regarding CCS industry & $\begin{array}{l}\text {-Lack of technical knowledge } \\
\text {-Lobbied by other industries }\end{array}$ \\
\hline Opportunities & Threats \\
-Giving subsidies, framework for co-operations & -Do not pay attention to CCS deployment \\
-Lobbied by CCS industry & \\
\hline
\end{tabular}

Table 3: SWOT analysis of the stakeholders: Policy makers/Regulators

Table 3 presents the SWOT analysis (Strengths, Weaknesses Opportunities, Threats) for policy makers. We assess they are the most influential stakeholders on CCS in Vietnam process. They have the opportunity to set the regulatory framework and to communicate to other stakeholders the importance of the CCS options. The State directly owns the main companies in the energy sector, and also has effective ties with the media and the education and training institutes.

Existing policies of Vietnam are not strong enough and lack of regulations to promote CCS application. Many environmental laws and regulations were enacted before CO2 became a concern. There is no regulation for land-use and monitoring long-time projects as CCS so far. The absence of regulation to classify CO2 emissions as a waste in Vietnam could inhibit CCS deployment.

CCS projects are only feasible with financial assistance, because they require substantial capital, and other low-carbon energy options are more competitive. At the moment, the Vietnam Environment Protection Fund is too weak to provide incentives to CCS projects. Most commercial banks in Vietnam are not strong enough to finance a CCS project, and lending would be severely limited by the risk due to uncertain policy framework.

In this context, the two scenarios are first differentiated by the government policy with respect to CCS. In one scenario, CCS is used only for EOR because the State keeps its hands off. In the other scenario, CCS is used at most gas and coal-fired power plants in Vietnam following a planned state intervention. Table 4 lists the assumptions setting the two scenarios apart with respect to the main drivers of the technology adoption. 


\begin{tabular}{|c|c|c|}
\hline Driving forces & $\begin{array}{l}\text { Low scenario: } \\
\text { CCS only EOR }\end{array}$ & $\begin{array}{l}\text { High scenario: } \\
\text { CCS in power }\end{array}$ \\
\hline Government stance on CCS & $\begin{array}{l}\text { Laisser-faire. Climate policy } \\
\text { instruments are generic }\end{array}$ & $\begin{array}{l}\text { Intervention to promote it with specific } \\
\text { incentives. }\end{array}$ \\
\hline Economic growth until 2050 & Trapped at middle-income level & Catches up with South Corea and Japan \\
\hline CCS technology costs & $\begin{array}{l}\text { A global ban on coal hurts CCS } \\
\text { scale up. }\end{array}$ & $\begin{array}{l}\text { General adoption of CCS in China and } \\
\text { elsewhere push costs down }\end{array}$ \\
\hline Carbon price trajectory & $\begin{array}{l}\text { Implicitly weak, below 30USD/tCO }{ }_{2} \\
\text { in } 2050\end{array}$ & $\begin{array}{l}\text { Most nations adopt a notional price of } \\
\text { carbon reaching } 50 \mathrm{USD} / \mathrm{tCO}_{2} \text { in } 2050\end{array}$ \\
\hline Social acceptance & $\begin{array}{l}\text { No, an international convention } \\
\text { against onshore CCS is discussed. }\end{array}$ & Yes, most storage in Vietnam is offshore \\
\hline Alternative technologies & Solar and wind win the cost race & $\begin{array}{l}\text { Coal with CCS remains more expensive } \\
\text { for new capacities, but capture-ready } \\
\text { plants are retrofit rather than closed. }\end{array}$ \\
\hline
\end{tabular}

Table 4: CCS scenarios: Driving forces

\subsection{Low Scenario narrative: EOR CCS only}

The context of the low scenario is that the growth of Vietnam's economy in next decades would not be as strong as expected, it remains in the middle-income class. Vietnam does not set quantitative targets to control its CO2 emission level in absolute terms before 2030.

Technical and societal constraints hinder the deployment of large-scale CCS in the world. Thus the effects of scale and technology learning progress are limited. The costs of technology does not fall rapidly, and CCS remains by 2050 a relatively expensive option for reducing GHG emissions, compared to solar and wind energy with battery storage. There are environmental and social issues with a few early carbon storage projects, which lead to a global movement against onshore geological storage. While these incidents do not happen in Vietnam, they bear in the country which is densely populated and well connected.

In addition to cost issues, investments are discouraged by risks created by international disputes about the control some of the best storage fields off shore between Vietnam, Philippines, China and other countries. There are no attractive international carbon trading schemes where Vietnam can take advantages of reducing its CO2 emissions.

With factors presented above, CCS incentives and regulatory measures remain inexistent. The country never issues policies to encourage the deployment of CCS. The main players to develop CCS projects are from the private sector. A joint management of storage projects is implemented at the local and industrial level. There are training programs for engineers and technicians who can work for CCS projects, but they are pushed by a few industrial sectors and located in other Asian countries.

In this future, Vietnam develops CCS projects exclusively in oil and gas industry where the recovery of $\mathrm{CO} 2$ can contribute to lower costs because oil recovery allows a return on investment. In this scenario, CCS occurs only at EOR projects like the one in the White Tiger 
field. One 250 MWe gas-fired CCS power plant comes online in 2024, and five years later 750 MWe of gas-fired CCS power generation capacity comes online, co-located in the same hub in the South region of Vietnam. No additional CCS generation capacity comes online after 2030. The main CO2 transport method used is shipping by boat, internationally within the Asia region. There is an international ban on producing $\mathrm{CO} 2$ from pure natural $\mathrm{CO} 2$ fields, but natural gas processing facilities can still sell their CO2 for EOR as a by-product. Another part of the CO2 used for EOR comes power plants and industries located in a few port cities in affluent Asian countries that have a significant carbon price.

\subsection{High Scenario narrative: CCS at all coal and gas power plants by 2050}

This scenario describes a future where CCS is used at all gas and coal-fired power plants in Vietnam in 2050.

In this scenario, the economy of Vietnam keeps growing fast. By 2050 it is above the middleincome status. Transformation into a high-density urban society leads to a greater demand for environmental quality by citizens. The knowledge-based economy allows for rapid progress in energy efficiency, which matches the increase the demand for energy. Considering that there are enough announced coal power plants to realize the Power Development Plan VII adjusted, the government suspends indefinitely the authorization of new coal power plants. Coal-fired power plants do dominate the generation sector of Vietnam from 2020 onward. The total capacity of coal-fired power plants would increase to 55 GW by 2030 .

CCS finally takes off in the international context, as China, Australia, South Africa and a few other countries consider it a Nationally Appropriate Mitigation Action. This reduces the technical barriers, and drives down the costs of CCS technology to a point where an affluent Vietnam can afford it by 2040. Vietnam and other countries in the region benefits CCS capacity building programs from IEA, ASEAN, APEC and industry associations.

In this scenario, storage activities are still initially driven by the oil industry, who seeks to extend the end life of offshore oilfield by $\mathrm{CO} 2$ flooding. But the government plays a central role early on. Incentive systems (e.g. taxes, subsidy ...) are implemented, as soon as 2020 for R\&D, to setup a pilot project. As in the previous scenario, 250 MWe of CCS gas-fired capacity comes online in 2024, and 750 MW more in 2029. However, these pilots are part of a long term strategy. The government announces that coal fired power plants build after 2020 will have to be capture-ready. The electricity generation sector is an active player for CO2 transport activities. In collaboration with provincial authorities, two CO2 hubs are setup in the country: one in Hai Phong, the other in the south. The CO2 collected exits the hubs both by pipelines, and a small fraction by ship, depending on market conditions.

The last classical coal-fired power generation unit is installed in 2030. After a four-year pause, a sixteen years retrofit program starts in 2035, to completely eliminate non-CCS coal and gas fired power plants by 2050 . 


\section{Quantitative analysis of the High CCS scenario}

\subsection{Model and data}

The High CCS scenario explores the proposition "CCS will be used in all coal and gas power generation plants by 2050 in Vietnam”. To quantify it compared to a baseline without CCS, we build a national energy mix simulation model. This model computes the system Levelized Cost of Electricity Generation (LCOE) and the system greenhouse gases emissions. It is a standard bottom-up representation of the energy system with twelve technologies: three fossil fuels, big hydro, four renewable energy technologies, coal CCS, gas CCS, bio CCS, and imports.

Mathematically, it can be considered a subset of Howells et al. (2011) OseMOSYS limited to the equations blocks about Objective, Total Discounted Cost, Operating Cost, Capital Costs, Salvage Value, Emissions, that is without optimization and constraints, without energy storage or within-year time slices. The model is in Python 3.5. For more details, code and data are available under the Creative Commons Attribution Sharealike International license at : https://github.com/MinhHaDuong/VN-CSS-Scenario.

Results depend on an annual expansion plan for the power sector up to 2050, and on technicoeconomic parameters describing the future performance of energy generation technologies and market conditions: EVN (2016) inventory was used to input today's installed capacities. The future capacity addition up to 2030 follow official Power Development Plan 7 revised in 2016 by the Government of Vietnam. Data for technical and economic parameters come from the OpenEI Transparent Cost Database (2017), and technology emission factors from IPCC SRREN (Moomaw et al. 2011, Table A.II.4 page 982). We used the median value of studies reported in these sources, see Table 5.

In the reference parameters set, LCOE is computed at a $6 \%$ discount rate. The LCOE does not includes external pollution costs. To value the greenhouse gas emission reduction, we assumed a cost of carbon at zero until 2020, rising to $50 \mathrm{USD} / \mathrm{tCO} 2 \mathrm{eq}$ in 2030, and to $100 \mathrm{USD} / \mathrm{tCO}$ eq in 2050. in the reference case. 


\begin{tabular}{|c|c|c|c|c|c|c|c|c|c|c|c|c|}
\hline & Coal & Gas & Oil & BigHydro & SmallHydro & Biomass & Wind & Solar & CoalCCS & GasCCS & BioCCS & Import \\
\hline Plant accounting life (year) & 40 & 25 & 30 & 100 & 60 & 25 & 20 & 25 & 40 & 25 & 25 & 100 \\
\hline Emission factor (gCO2eq/kWh) & 1001 & 469 & 840 & 4 & 4 & 18 & 12 & 46 & 247 & 155 & -981 & 502.5 \\
\hline Capture factor (gCO2/kWh) & 0 & 0 & 0 & 0 & 0 & 0 & 0 & 0 & 1054.3 & 454.7 & 1004.4 & 0 \\
\hline Overnight construction costs $(\$ / \mathbf{k W})$ & 3483 & 942 & 815.3 & 2843.4 & 1730 & 3324.5 & 3286 & 4568.1 & 4347.5 & 1845 & 4149.6 & 500 \\
\hline Overnight construction costs trend $(\$ / \mathrm{kW} / \mathrm{y})$ & 0 & 0 & -8.4 & 0 & 0 & 0 & -15 & -64.2 & 0 & 0 & 0 & 0 \\
\hline Fixed operating costs $(\$ \mathbf{k W})$ & 31.2 & 10.9 & 10.4 & 15 & 17.6 & 112.3 & 67.9 & 47.9 & 68.5 & 30.8 & 246.8 & 0 \\
\hline Fixed operating costs trend ( $\$ / \mathbf{k W} / \mathbf{y r})$ & 0 & 0 & 0 & 0 & 0 & 0 & -0.6 & -0.5 & 0 & 0 & 0 & 0 \\
\hline Variable operating costs $(\mathbf{\$} / \mathbf{k W h})$ & 6.2 & 3.6 & 6.9 & 2.5 & 3.5 & 6.1 & 0 & 0 & 8.4 & 6.6 & 8.2 & 60.8 \\
\hline Heat rate (Btu/kWh) & 8800 & 7310 & 9508 & 0 & 0 & 13500 & 0 & 0 & 11440 & 9503 & 17550 & 0 \\
\hline Heat price (\$/MBtu) & 2.3 & 4.4 & 4.4 & 0 & 0 & 2.3 & 0 & 0 & 2.3 & 4.4 & 2.3 & 0 \\
\hline
\end{tabular}

Table 5: Model parameters. 


\subsection{The scenario}

Figure 3 shows the total generation capacity in Vietnam for the baseline scenario (top) and the High CCS scenario (bottom). The time axis runs from 1974 to 2050, with vertical bars at 2015 -the end of the historical period- and 2030- the government's planning horizon. The two panels are identical before 2015, in the historical period. Before 2030, the only difference is that in the High CCS scenario, 1GW of CCS gas generation capacity replaces $1 \mathrm{GW}$ of nonCCS gas generation capacity: in the bottom panel, the grey dashed line takes off before 2030 . After 2035, the two plans remain identical for renewable energy, imports, and total electricity production. They differ as follows:

In the baseline scenario, we assumed no new coal or big hydro after 2030, and every year $+750 \mathrm{MW}$ of new gas-fired capacity, $+900 \mathrm{MW}$ of wind and $+1000 \mathrm{MW}$ of solar. Oil, small hydro, biomass and imports also grow at more modest rates, +20 to 50MW per year. All curves flatten out or peak in the 2040-2050, as these installation rates are not enough to replace the old plants being retired.

In the High CCS scenario, from 2035 onwards Coal CCS replaces Coal capacity, about 3.2GW per year. This corresponds to retrofitting five 600MW generation units. Also, Gas CCS substitutes for Gas capacity, for $1.4 \mathrm{GW}$ per year. This corresponds to retrofitting a 650MW gas generation unit, and building the new yearly 750MW Gas with CCS. This is what is necessary to replace by 2050 all non-CCS coal and gas generation capacity programmed today by the PDP7A. The scenario ramps up biomass CCS capacity at increasing speed, starting from 0 in 2035 to $150 \mathrm{MW} / \mathrm{yr}$ in 2050. In total biomass CCS reach only $1.2 \mathrm{GW}$ in 2050, the green dashed line remains close to the bottom. 
Generation capacity by technology, 1975 - 2050
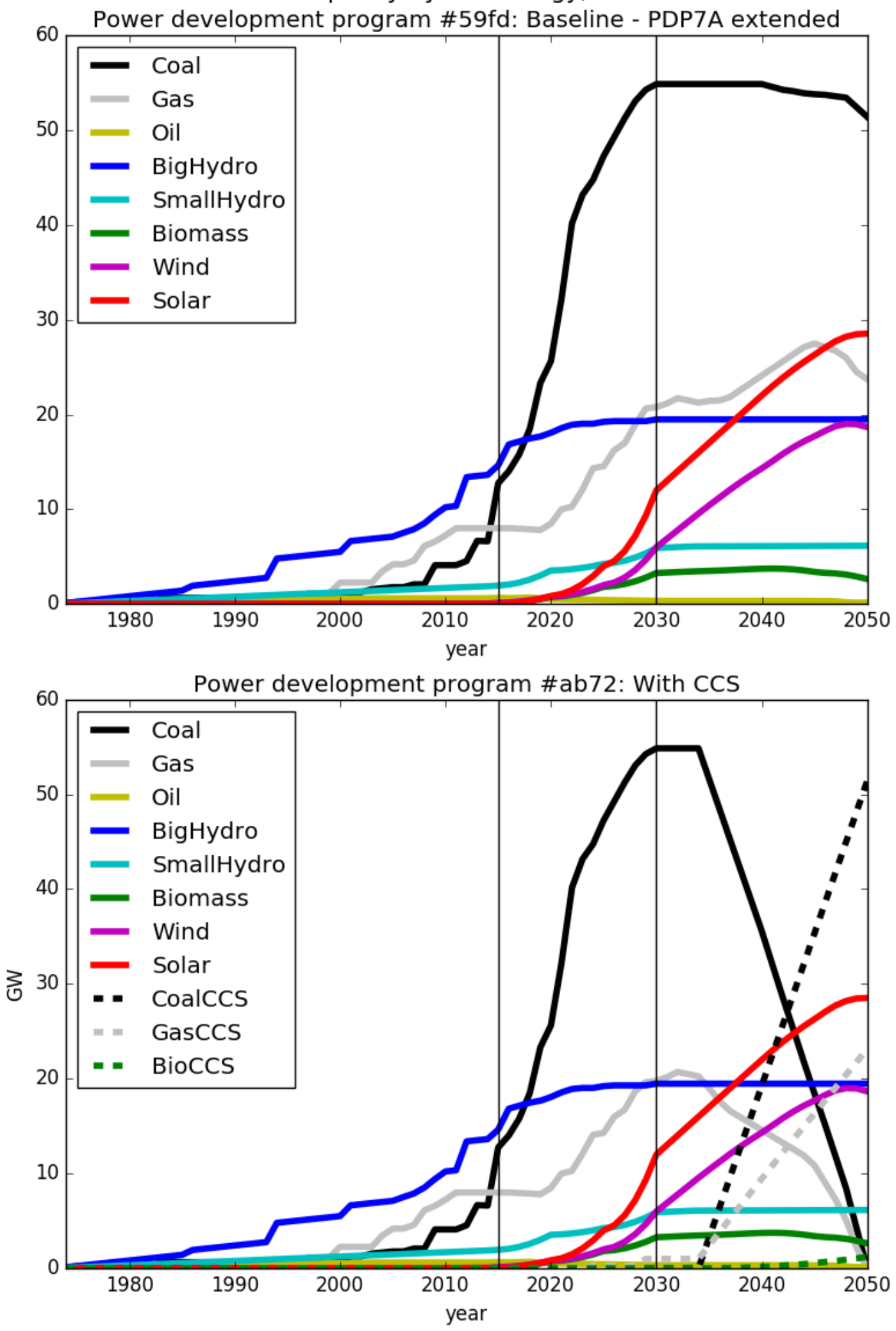

Figure 3: Generation capacities by fuel type, 1975-2050. Top: Baseline, Bottom: With CCS. Vertical bars at 2015 and 2030. 


\subsection{Results and sensitivity analysis}

In terms of carbon capture, the High CCS scenario captures 2 Mt CO2/y in 2030 at the end of the pilot program. This number reaches $23 \mathrm{Mt} \mathrm{CO2/y} \mathrm{captured} \mathrm{in} \mathrm{2035,} \mathrm{for} \mathrm{the} \mathrm{first} \mathrm{year} \mathrm{of}$ the CCS program. Then it increases by the same amount every year, to $123 \mathrm{Mt} \mathrm{CO2/y} \mathrm{in} 2040$ and $311 \mathrm{MtCO} 2 / \mathrm{y}$ in 2050.

In the baseline plan, the Average Carbon Intensity of electricity increases from $498 \mathrm{gCO} 2 / \mathrm{kWh}$ in 2016 to 654 gCO2/kWh in 2030 before falling back to 546 gCO2/kWh in 2050. This is the consequence of the energy mix shifts. As Figure 3 shows, fossil fuels dominate the mix in 2030, but in 2050 solar and wind's share have increased. In the High CCS plan, the Average Carbon Intensity of electricity drops to only 146 gCO2/kWh in 2050.

Tables 6 summarizes the scenarios' comparison. While the system is mostly low-carbon in 2050 in the High CCS scenario, in terms of total CO2 emitted during the period, the two scenarios are less contrasted: $11.1 \mathrm{GtCO}$ eq for the baseline, 8.9 GtCO2eq emitted and 2.7 GtCO2 captured for the High CCS scenario. Converting all fossil fuel power plants to CCS by 2050 saves $2.2 \mathrm{GtC}$ in the first half of the century. With the given carbon price trajectory, this amounts to 39 billion USD.

The LCOE increases from 65 cent/kWh in the baseline case to 6.99 cent/kWh in the High CCS scenario. This corresponds to an increase in total system cost (discounted on 2016-2050 at $6 \%$, not including externalities) from 386 to 446 billion dollars - that's a 60 billion USD 2016 increase. In terms of cost-benefit analysis, for the reference parameters set, the mitigation of greenhouse gas emissions is not enough to justify the CCS retrofit program: it remains more expensive by 26 billions even when the costs of $\mathrm{CO} 2$ emissions is included.

\begin{tabular}{lllll}
\hline & Baseline & High CCS & difference & Units \\
Power produced & 6385 & 6385 & 0 & Twh \\
System LCOE & 60.5 & 69.9 & 9.4 & USD/MWh \\
Total cost & 386 & 446 & 60 & bn USD \\
Construction & 211 & 268 & 57 & bn USD \\
Fuel cost & 109 & 113 & 4 & bn USD \\
O\&M & 75 & 80 & 5 & bn USD \\
Salvage value & -9 & -15 & -6 & bn USD \\
CO2 emissions & 11.1 & 8.9 & -2.2 & GtCO2eq \\
CO2 capture & 0 & 2.7 & 2.7 & GtCO2 \\
CO2 cost & 173 & 139 & -34 & bn USD \\
Cost with CO2 & 559 & 585 & 26 & bn USD \\
\hline
\end{tabular}

Table 6: Comparison of Baseline and High CCS scenario results.

Sensitivity analysis show that if the carbon price is uniformly increased by $175 \%$ compared to the reference parameters (up to 175 USD/tCO2eq in 2050), then the High CCS plan becomes as interesting as the baseline plan with respect to the total system cost including $\mathrm{CO} 2$. We 
suppose that increasing the model horizon would also increase the relative advantage of the High CCS scenario in terms of cost of CO2 emissions, depending on the discount rate.

We examined the assumption that CCS technology cost fall by $1.8 \%$ per year for both construction and operation \& maintenance. This is the rate at which High CCS scenario becomes as interesting as the baseline, in terms of system cost including $\mathrm{CO} 2$ costs. In this case, the LCOE of the High CCS plan is 6.58 cent $/ \mathrm{kWh}$, compared to $65 \mathrm{cent} / \mathrm{kWh}$ in the baseline and to 6.99 cent/kWh when CCS costs were assumed constant. This is about half closer to the baseline cost, but still a price increase that consumers would notice.

Finally, we tested the assumption that coal and gas prices fall by 3\% per year. In this case, the fuel costs drop from 109bn USD to 74bn USD in the baseline plan, and from 113bn USD to 86bn USD in the High CCS plan. In terms of discounted net present value, the baseline benefits from lower fuel prices more than the High CCS does. 


\section{Discussion}

\subsection{Challenges and opportunities for moving from the low- to high- scenario in Vietnam}

Despite CCS's advantages, Vietnam could face several obstacles if the country uses these technologies to reduce $\mathrm{CO} 2$ emissions in the coming decades. Those obstacles concern the following: technology, environment, energy security, finance, and policy. More efficient solutions that Vietnam could propose to deal with problems identified, faster and larger CCS project could be developed in the countries in coming time. In the high scenario, $\mathrm{CO} 2$ emission from the future energy sector of Vietnam could achieve a deep cut due to large scale of CCS utilities in the power generation sector. Followings are some challenges and solutions for Vietnam to increase the likelihood of moving from the low- to high- scenario with its domestic resources.

Financial and political barriers remain important issues. Currently there is no room for CCS in the short-term because under the current regulations of the energy sector of Vietnam, investment costs of CCS in power plants are not taken into the depreciation period and then not into the cost of electricity generation. To cover the costs of CCS technology and the additional fuel consumption to run the CCS systems, the power plant operators can expect only the revenue from selling the credits of their $\mathrm{CO} 2$ emission reduction. This revenue would depend on not only the reduction, which they can technically control, but also the market price of $\mathrm{CO} 2$.

Policy is definitely the most important initial factor for Vietnam to bring CCS technology in the country. To promote and manage CCS projects, Vietnam should establish a special board operated under the following five ministries: Ministry of Industry and Trade, Ministry of Environment and Natural Resources, Ministry of Science and Technology, Ministry of Investment and Planning and Ministry of Finance. Integrating CCS technology in the power sector should be given, at the least, the same incentives as other clean electricity generation technologies, such as technology imports, taxes, loan interest, and land use. In addition, the investment of capture readiness in new power plants should be depreciated in the same way as other investment costs and included in the cost of electricity generation before CCS technology is integrated.

Additional energy consumption due to CCS implementation in power plants is a problem. Noted that the processes to capture, to transport and to inject CO2 would consume a considerable amount of energy that increases primary fuel consumption of fossil fuel-based power plants. In other words, a power plant that integrates CCS technology needs more fuel to generate the same amount of electricity compared with a similar plant without CCS technology. In the most optimistic scenario where financial credits gained due to the reduction of CO2 emission, CCS technology could help coal power plants reduce their total generation costs. However, if CCS technology is implemented on a large scale, Vietnam would need to burn more fossil resources to fuel its economy that would increase the concern of energy balance in the country. In the case, standards for $\mathrm{CO} 2$ emissions and technologies to reduce 
these emissions would be stated clearly in the strategy. In addition, standards for more power efficiency in power plants could reduce the additional energy consumption of the CCS infrastructure.

To address environmental issues presented earlier in 3.4, standards for environmental protection and clear risk management at $\mathrm{CO} 2$ production sources, storage sites and on transportation systems should be designed by stakeholders and approved by the government of Vietnam. In fact, some regulations require the control of other types of air pollutants, such as $\mathrm{CO} 2$ and NOx, such as coal-fired power plants with static electric air controllers. More regulations for $\mathrm{CO} 2$ emissions are needed when the country starts developing CCS projects.

Because there are insufficient studies regarding CCS potential in Vietnam, there is a need for more studies to not only examine Vietnam's potential for CO2 storage capacity but also to analyse its technical and economic aspects. In addition, these studies should consider external costs and assess the environmental and social impacts of CCS projects at the local level to calculate the full cost of this technology. Scenarios to respond to accidents, such as leakages or interactions with water, heavy metals, particulates and acid gases that may occur during the transportation and storage of CO2, should be developed to demonstrate the safety of CCS projects. A scientific mechanism to control and monitor the CCS project should be implemented to avoid unsafe operation.

Although Vietnam could take advantage of its various renewable energy sources to meet its power demand as well as reduce $\mathrm{CO} 2$ emissions rather than burn coal then apply expensive technology, CCS could be not first but must-be-considered option which should be supported by the Government. Vietnam's energy system and environment are so fragile that CCS technology must be implemented only if it can be proved safe. In general, there are still risks to the environment and the energy system that prevent CCS development on a commercial scale but Government should play a key role in funding and policy making. In the short term, financial incentives are the main approach for investment in CCS technology. In the long term, however, a sound business environment that is characterized by mature technology, market-oriented mechanisms for price, and a complete legal system should be established.

\subsection{Policy discussion}

Given that two of the biggest challenges for the development of CCS in Vietnam are high costs and risks, the government is not optimistic regarding CCS technology, and the scientific institutes have no in-depth research on it, which led to little attention to CCS from the industrial sector. If Vietnam was asked to take a national position towards CCS, it would logically be that CCS is expensive and should be developed by rich countries that have an historical responsibility in climate change. Without international financial supports and necessary technology transfers, Vietnam could only be interested in CCS as far as it contributes to the energy security of the country. Although EOR may positively contribute to the primary energy supply, CCS in power plants increases the consumption of fuels. As coal is more and more imported for higher power demand, CCS would actually affect negatively the 
energy security issue in the country. Whether international cooperation or carbon finance can support CCS in Vietnam also remains to be seen.

For these reasons, the scenario "CCS EOR only" appears to us closer to business as usual than the scenario "CCS in power". However, the future is open, and the "CCS in power" scenario is much more compatible with a world avoiding a dangerous level of global warming. International and national climate policies are progressing fast, so both scenarios remain plausible. In our opinion, energy policy in Vietnam should not indefinitely defer thinking hard about CCS for the following reasons:

- Given Vietnam's plans to expand the use of coal to produce electricity, questions on CCS will inevitably have to receive answers someday. These answers will depend a lot on the decisions taken about building capture ready today or not.

- As demonstrated by the White Tiger project, there are opportunities for EOR by CO2 injection in Vietnamese oil fields. These could reduce storage costs or even produce a storage co-benefit, enhancing the cost-competitiveness of CCS (Metz et al. 2005). provided that enhanced oil production onshore with CCS could generate 10-16 \$/tCO2 of net benefits. This was with oil prices before 2003. Benefits of deploying CCS with EOR will rise proportionally to oil prices in the long run.

- There are international cooperation efforts pushing towards the development of CCS in third countries under flexibility mechanisms. International or bilateral agreements may offer ways to finance CCS projects in developing countries. For example, there are low-hanging fruits in the natural gas processing sector. Vietnam might benefit from such financial mechanisms. Networking and capacity building, for example by joining global CCS institutes and research forums, could help to be ready by then.

China has world-leading research at universities, with policies and industry incentives for CCS demonstration and early deployment. Indonesia designated the national R\&D center for oil and gas technology as the focal point in performing specific research and development of CCS. In contrast, in Vietnam there is currently very few, if any, research centre with the necessary facilities and infrastructures to study the conditions of CCS development. Research centers currently performing R\&D activities related to energy and climate change could be involved in CCS research, at least to clarify the strategic position in the wider reflexion on the climate change, energy sources and development policy.

Many countries are in the process of building the legal frameworks for CCS. International cooperation/collaboration could provide Vietnamese lawmakers with examples. An early integration of CCS ready regulations into the current approval processes for thermal power projects could help to facilitate the adoption of CCS later, and assist project developers in assessing the feasibility of their plant being storage ready. 


\section{Conclusion}

The two scenarios we presented are original -as in previously unpublished- but also not original -as in generic, not surprising to any expert in the field. In the low scenario CCS develops for EOR, about 1GW of pilot plants are build by 2030 but no more. In the high scenario, CCS is used all coal and gas power plants by 2050, mainly by retrofit. This is because they are unsurprising that these scenarios are plausible. Both should be considered for long-range business and policy planning.

Vietnam has promising geological formations for CO2 storage less than $100 \mathrm{~km}$ away from present and future fossil-fuel power plants. It could technically play a significant role in the deployment of CSS among the ASEAN countries, however there is no commitment to the technology in Vietnam, not even much interests in CCS research and development. A scenario in which CCS is used in fossil-fuel power plants in Vietnam cannot be excluded. There is a real option value to building capture-ready power plants today.

In developing countries, the energy policy goals are to provide affordable energy to the whole population, and enhance and sustain energy security. For this, the immediate priorities are to increase the energy efficiency and add generation capacity. The Government of Vietnam has concerns about climate change and its negative impacts. But as of late 2016 it is still forming action plans to reduce carbon emissions in next few decades. It remains to be seen if CCS is part of these plans. 


\section{Acknowledgements}

We acknowledge the support of Dr. Didier Bonijoly, BRGM, with respect to the geological

information. Dr. Nguyen Tran Nhan contributed to this research's initial stage while doctoral student at CIRED. 


\section{References}

ADB. 2012. Prospect for Carbon Capture and Storage In Southeast Asia. Asian Development Bank. http://www.adb.org/publications/prospects-carbon-capture-and-storage-southeast-asia.

APEC. 2005. "CO2 Storage Prospectivity of Selected Sedimentary Basins in the Region of China and South East Asia.” Asia Pacific Economic Cooperation. http://www.globalccsinstitute.com/publications/co2-storageprospectivity-selected-sedimentary-basins-region-china-and-south-east-asia.

Aruna K. Wanniachchi, Duy-Thanh Bui, Hyunjung Lee, Choon-Sik Jung, and Au Minh Tuan. 2016. Viet Nam Energy Sector Assessment, Strategy, and Road Map. Asian Development Bank and Asian Development Bank Institute.

Asian Development Bank (ADB). 2009. The Economics of Climate Change in Southeast Asia: A Regional Review. http://www.adb.org/Documents/Books/Economics-Climate-Change-SEA/default.asp.

Audinet, Pierre, Bipulendu Nrayan Singh, Duane T. Kexel, Suphachol Suphachalasai, Pedzisayi Makumbe, and Kristin Mayer. 2016. “Exploring a Low-Carbon Development Path for Vietnam.” Washington, D.C.: World Bank Group. http://documents.worldbank.org/curated/en/773061467995893930/Exploring-alow-carbon-development-path-for-Vietnam.

Boden, T. A., G. Marland, and R. J. Andres. 2013. “Global, Regional, and National Fossil-Fuel CO2 Emissions.” Carbon Dioxide Information Analysis Center (CDIAC),Environmental Sciences Division, Oak Ridge National Laboratory. https://doi.org/10.3334/CDIAC/00001_V2013.

Bohm, M.C. 2007. “Capture-Ready Coal Plants - Options, Technologies and Economics.” International Journal of Greenhouse Gas Control 1: 113-20.

British Petroleum. 2016. “BP Statistical Review of World Energy.” http://oilproduction.net/files/especial-BP/bpstatistical-review-of-world-energy-2016-full-report.pdf.

Bureau des Recherches Géologiques et Minières (BRGM). 2009. “Où sont les capacités de stockage du CO2 au Viet Nam ?” In Forum Économique et Financier, Huitième Session, Énergie et Développement Durable. Ha Long, Vietnam: ADETEF. http://www.adetef.org.vn/website/index.php? option=com_content\&task=blogcategory\&id=30\&Itemid=58.

CCICED. 2009. “China’s Pathway toward a Low Carbon Economy.” Policy Research Report 2009. The China Council for International Cooperation on Environment and Development. http://www.cciced.net/encciced/policyresearch/report/201205/P020120529358137604609.pdf.

Christopher Short. 2010. “Global Knowledge Sharing Framework.” Global CCS Institute. http://www.globalccsinstitute.com/insights/authors/christophershort/2010/11/03/definition-ccs-ready.

DNV. 2005. “The White Tiger Oil Field Carbon Capture and Storage (CCS) Project in Vietnam.” Project Design Document, Initial Submission NM0167. Executive Board of the Clean Development Mechanism. http://cdm.unfccc.int/methodologies/PAmethodologies/pnm/byref/NM0167.

EVN, 2016. “Vietnam Electricity Annual Report 2016”, Electricity of Vietnam 2016, http://www.evn.com.vn/userfile/files/2017/3/AnnualReport2016.pdf

GCCSI. 2016. “The Global Status of CCS.” 2016. Accessed October 6. http://status.globalccsinstitute.com/.

GSO, General Statistical Office. 2015. Statistical Handbook of Vietnam 2014. Statistical Publishing House. http://www.gso.gov.vn/default_en.aspx?tabid=515\&idmid=5\&ItemID=15197.

GSO, General Statistical Office. 2016. Statistical Handbook of Vietnam 2015. Statistical Publishing House. http://www.gso.gov.vn/default en.aspx?tabid=515\&idmid=5\&ItemID=16003

Howells, Mark, Holger Rogner, Neil Strachan, Charles Heaps, Hillard Huntington, Socrates Kypreos, Alison Hughes, et al. 2011. OSeMOSYS: The Open Source Energy Modeling System: An Introduction to Its Ethos, Structure and Development. Energy Policy, Sustainability of biofuels, 39, no. 10 (October 2011): 5850 70. doi:10.1016/j.enpol.2011633. 
H. Liu. 2010. “Catalyzing Strategic Transformation to a Low-Carbon Economy: A CCS Roadmap for China.” Energy Policy 38.

H.A Nguyen-Trinh and M Ha-Duong. Perspective of CO2 capture \& storage (CCS) development in Vietnam: Results from expert interviews. International Journal of Greenhouse Gas Control, 37:220-227, 2015

IEA. 2007. “CO2 Capture Ready Plants.” Technical Study in support of the G8 Plan of Action 2007/4. International Energy Agency. https://www.iea.org/publications/freepublications/publication/CO2_Capture_Ready_Plants.pdf.

Indonesia CCS Study Working Group. 2009. “Understanding Carbon Capture and Storage Potential In Indonesia.” www.ukccsrc.ac.uk/system/files/ccspotentialindonesia.pdf.

International Energy Agency, Greenhouse Gas R\&D Programme (IEA GHG). 2008. CO2 Capture and Storage. A Key Carbon Abatement Option. International Energy Agency - Energy Publications. http://www.iea.org/textbase/nppdf/free/2008/CCS_2008.pdf.

Kimura, Shigeru, and Han Phoumin. 2016. “Energy Outlook and Energy Saving Potential in East Asia 2016.” Books. Economic Research Institute for ASEAN and East Asia (ERIA). https://ideas.repec.org/b/era/eriabk/2015-rpr-05.html.

KVN (Département de géologie et des minéraux du Viet Nam). 2009. “KHA NĂNG THU GIU KHÍ CO2 TAI VIET NAM ĐÉN ĐÂU ?” In Forum Économique et Financier, Huitième Session, Énergie et Développement Durable. Ha Long, Vietnam: ADETEF. http://www.adetef.org.vn/website/index.php? option=com_content\&task=blogcategory\&id=30\&Itemid=58.

Li, Jia, Xi Liang, and Tim Cockerill. 2011. “Getting Ready for Carbon Capture and Storage through a 'CCS (Carbon Capture and Storage) Ready Hub’: A Case Study of Shenzhen City in Guangdong Province, China.” Energy 36 (10): 5916-24. doi:10.1016/j.energy.2011830.

Li, Jia, Xi Liang, David Reiner, Jon Gibbins, Mathieu Lucquiaud, and Hannah Chalmers. 2011. "Financing New Power Plants ‘CCS Ready’ in China-A Case Study of Shenzhen City.” Energy Procedia, 10th International Conference on Greenhouse Gas Control Technologies, 4 (January): 2572-79. doi:10.1016/j.egypro.20112.155.

Liang, Xi, David Reiner, Jon Gibbins, and Jia Li. 2010. "Getting Ready for Carbon Capture and Storage by Issuing Capture Options.” Environment and Planning A 42 (6): 1286 - 1307. doi:10.1068/a42417.

Metz, Bert, Ogunlade Davidson, Heleen de Coninck, Manuela Loos, and Leo Meyer, eds. 2005. Carbon Dioxide Capture and Storage. Special Report of the Intergovernmental Panel on Climate Change. Cambridge University Press. http://www1.ipcc.ch/ipccreports/srccs.htm.

Moomaw, W., P. Burgherr, G. Heath, M. Lenzen, J. Nyboer, A. Verbruggen, 2011: Annex II: Methodology. In IPCC Special Report on Renewable Energy Sources and Climate Change Mitigation [O. Edenhofer, R. Pichs-Madruga, Y. Sokona, K. Seyboth, P. Matschoss, S. Kadner, T. Zwickel, P. Eickemeier, G. Hansen, S. Schlömer, C. von Stechow (eds)], Cambridge University Press, Cambridge, United Kingdom and New York.

National Load Dispatch Center. 2012. “Annual Report 2012.”

Nguyen, Khanh Q. 2008. “Internalizing Externalities into Capacity Expansion Planning: The Case of Electricity in Vietnam.” Energy 33 (5): 740-46. doi:10.1016/j.energy.2008114.

Nguyen, Nhan Thanh. 2011. "Programmer Le Développement Soutenable Dans Un Pays En Voie de Développement: Une Optimisation Sociale Du Secteur Électrique Au Vietnam.” Paris, France: Ecole des hautes études en sciences sociales - EHESS. http://tel.archives-ouvertes.fr/tel-00593573.

Nguyen, Tan Dung. 2016. QUYET DINH Phe Duyet Dieu Chinh Quy Hoach Phat Trien Dien Luc Quoc Gia Giai Doan 2011 - 2020 Co Xet Den Nam 2030. http://vanban.chinhphu.vn/portal/page/portal/chinhphu/hethongvanban? class_id=2\&mode=detail\&document_id=183986. 
Nguyen Tan Dung, The Prime Minister. 2016. Decision Approving the Adjusted Master Plan on Development of Vietnam's Coal Industry through 2020, with Prospects toward 2030 Taken into Consideration. http://vietnamlawmagazine.vn/decision-no-403-qd-ttg-of-march-14-2016-5391.html.

Nguyen-Trinh, H.A., and Minh Ha-Duong. 2015. "Perspective of CO2 Capture \& Storage (CCS) Development in Vietnam: Results from Expert Interviews.” International Journal of Greenhouse Gas Control 37 (June): 220-27. doi:10.1016/j.ijggc.2015319.

Nguyen-Trinh, Hoang Anh, and Minh Ha-Duong. 2016. "Low Carbon Scenario for the Power Sector of Vietnam: Externality and Comparison Approach.” GMSARN International Journal 4 (3): 137-46.

Nubuo Imai, and Scott Reeves. 2004. "Feasibility Study on CO2 EOR of White Tiger Field in Vietnam.” presented at the Third Annual DOE Conference on Carbon Capture and Sequestration, Alexandria, VA, USA, May 3.

Sekar, R.C. 2007. "Future Carbon Regulations and Current Investments in Alternative Coal-Fired Power Plant Technologies.” Energy Policy 35.

Tharakan, P. 2011. “Technical Assistance Proposal: Carbon Capture \& Storage South East Asia.” http://siteresources.worldbank.org/INTENERGY2/Resources/41141911316103699379/Tharakan_WB_CCS_ADB.pdf.

The Government of Vietnam. 2016. "The Adjustments of 7th Vietnam Power Development Planning."

Transparent Cost Database. (2017). Open Energy Information (en). Accessed 2017-05-10: http://en.openei.org/wiki/Transparent_Cost_Database.”

World Bank. 2010. "Winds of Change: East Asia’s Sustainable Energy Future.”

Zero Emission Resource Organisation. 2010. "White Tiger Ccs Project.”

Zhou, Di, Daiqing Zhao, Qiang Liu, Xiao-Chun Li, Jia Li, Jon Gibbons, and Xi Liang. 2013. "The GDCCSR Project Promoting Regional CCS-Readiness in the Guangdong Province, South China.” Energy Procedia, GHGT-11 Proceedings of the 11th International Conference on Greenhouse Gas Control Technologies, 18-22 November 2012, Kyoto, Japan, 37 (January): 7622-32. doi:10.1016/j.egypro.20136.708.

Zhu, Lei, and Ying Fan. 2013. "Modelling the Investment in Carbon Capture Retrofits of Pulverized Coal-Fired Plants.” Energy 57 (August): 66-75. doi:10.1016/j.energy.2013372. 